\title{
The Contribution of Saudi Woman in Environmental Development
}

\author{
Haga Elimam and Halah Alattas
}

\begin{abstract}
The Kingdom of Saudi Arabia is concerned with increasing the environmental awareness and securing a sustainable, healthy environment. The country also aims to encourage the role of women in this respect. In addition to being a mother, educator and teacher, a woman can play a significant role in securing safe and healthy environment. A woman can also preserve the depleted natural resources through her wise dealing of these resources available in homes, such as water and energy. She can also educate children to use the resources of nature efficiently. This study finds tendency and concern for activating her role in preserving the environment and motivating the young generations for this noble cause.
\end{abstract}

Index Terms - Natural resources, environmental development, environmental awareness, health environment, resource exhaustion.

\section{INTRODUCTION}

The insertion of the environmental dimension in the economic field led to the changing of the economic development from sheer exploitation of rare economic resources to the satisfaction of various human needs to the concept of sustainable development, which reaffirms the concept of the environment protection and preservation of resources [1].

The concept of sustainable development necessitates the satisfaction of the needs of present time without prejudice to the ability of the next generation in achieving their demands because sustainable development does not prevent the exploitation of economic resources such as water, petrol and forests but does not prevent any? Exploitation of resources to the extent that affects the share of the next generations in these resources, especially if such resources are not renewable and exposed to exhaustion such as petrol or those that might be exhausted whether sooner or in later period. Furthermore, the sustainable development is keen that the next generations should not be held responsible for shouldering the burden of reforming and improving the environment that is contaminated by the current generations.

There was a distinction among the theories of the economic development in regards to the development that considers the environmental aspects and which is termed as "green development" and the pure economic development that does not take into account the environmental dimension and takes advantage of the environmental resources and exploits them in the service of the economy. This particular type of pure

Manuscript received January 12, 2015; revised May 13, 2015.

The authors are with the Department of Economics, Faculty of Economic and Administration at King Abdul-Aziz University, Kingdom of Saudi Arabia (e-mail: ana.imam@yahoo.com). economic development is constantly and strongly criticized by all circles including the international economic foundations to the extent that such development is described as "black development".

The international economic foundations have commenced to give much concern with the preparation of national accounts that consider the environmental dimension; and such accounts are termed as " the green national accounts" which are based on the fact that any improvement in the environmental circumstance and the economic resources is an increase in the assets of the state: and that any decrease in the economic resources or any damage on the environment is an increase in the obligations of the state and is consequently seen as a reduction in its assets.

\section{A. Objectives}

This study aims to know the current status of the Saudi woman and extent of her contribution in society as well as the ways that enhance her role in society, and confirm her participation in achieving developmental development.

\section{B. Significance}

This study is considered significant because it attempts to shed light on the role of the Saudi woman and the extent of her contribution in achieving environmental development as women folk constitute half of the society; and that they represent a significant productive source without prejudice to her essential role in the family. Moreover, the study provides development planners and decision makers with the required information.

\section{METHODOLOGY}

The study used the analytic descriptive method which is based on tackling and analyzing the published research and statistics as well as utilizing the Program of Statistical Package for Social Sciences (SPSS) for describing and analyzing the obtained data.

\section{THE ROLE OF THE WOMAN IN THE PRESERVATION OF ENVIRONMENT}

Based on her key familial function, the woman is considered an individual who is primarily responsible for many matters pertaining to environment; because she serves the role of the mother who is responsible for taking care of her children and that of the housewife who runs the affairs of her family, in addition to her role as a teacher. We can enumerate the roles of a woman as follows:

\section{A. Woman as an Educator and Guide}


The woman brings up generations and hence she can inculcate in the minds of her offspring since their early childhood the sense of responsibility towards environment: and that she can direct them to do the works that service environment and avoid those that destroy it. Generally speaking, a woman can set good example for both her offspring and others via following conduct that preserves environment; the simplest of which is to take the different types of garbage from her home and put them in the containers specified for them.

\section{B. The Woman as a Housewife}

The woman shoulders the responsibility of managing her home. This gives her a specific significance in combating the various types of pollution at home. Furthermore, she normally chooses goods, foodstuff, medicines, and clothes, etc. that suits best her family members; and that she can select environmentally friendly goods.

\section{The Woman Linked to the Rural Area}

The rural woman prepares land for various agricultural purposes, plants crops and pastures animals. Thus, she is considered the most concerned individual with the responsibility of the environmental problems, which include for instance - but not limited to - deterioration of the agricultural soil, continuation of the drought periods, contamination of water and pollution and spread of diseases. This essentially enhances her environmental role as her participation in the environment preservation activities contribute substantially to the solution of a number of environmental problems. The elite nature of education, and its biasness in favor of male, is responsible for the illiteracy of the rural women [2]. In fact, when you enlighten the woman on environment and call her to make a contribution to environment preservation, we at the same time disseminate the awareness among all members of the family members.

\section{The Woman as a Teacher}

In working as a teacher, a woman plays a significant role in the preservation of the environment. In fact, she can direct the students via school activities to feeling the responsibility of preserving and concerning with the environment as well as projecting erroneous behavioral practices that harm the environmental safety and that must be desisted from.

\section{E. The Role of the Woman in the Preservation of Environment from an Islamic Viewpoint}

The role which the woman should play in the preservation of environment does not only contribute to securing safe, healthy environment but it also achieves at the same time an excellent human objective that conforms to the duties of both male and female Muslim towards their living and environment. Furthermore, Allah Almighty has created this natural environment on which we live with specific characteristics, contents and quantities in a manner that secures appropriate, safe ways of life for mankind and the rest of other living beings which live with us on the surface of the earth.

\section{Allah Almighty says}

"And has created each thing and determined it with precisely” (Qur'an 25:2)

He also says

"Indeed, We created all things with due and required preciseness" (Qur'an 54:49)

These two particular Qur'anic verses indicate that the natural environment, in its ordinary condition, which is devoid of destructive and spoiling intervention by man, is balanced, for every factor of the natural environment has been created in specific characteristics, quantity and volume in a manner that guarantees equilibrium for the environment, and which is underlined by the following Qur'anic verse:

"We have spread the earth and cast therein firmly set of mountains and caused to grow therein every well-balanced things" (Qur'an 15:19).

Furthermore, this particular verse signifies that the unshakable mountains retain the balance of the earth. Additionally, Allah Almighty has created on earth everything with a limited known quantity. For, plants grow to meet the needs of /the living beings that nourish on such plants. Likewise, the types and numbers of plants are created in specific quantities that do not destabilize the environmental equilibrium.

We have to indicate here that the concept of environmental equilibrium does mean the retaining of the elements and components of the natural environment on the condition in which Allah has created it without any crucial alteration.

\section{THE SAUdi WOMAN AND ENVIRONMENTAL AWARENESS}

The preservation of the environment is greatly associated with culture and knowledge. There is an increased concern in the world towards environmental issues. The recent few years have also witnessed substantial concern with the development of the Saudi woman. Women are now seen as active participants in the process of innovation through their demonstrated capacities of innovation [3]. This naturally led to the increase of the degree of her environmental awareness. Furthermore, there was a serious concern with the limitation of waste materials and putting of garbage at the specialized containers for necessary disposal. Moreover, the contamination of the room's air with cigarette smoke has become a subject that disturbs the housewife who attempts to resist it by encouraging her husband to get rid of the bad smoking habit. Likewise, the issue of economizing water consumption at home is considered significant, and that many housewives tend to abide by it whether at kitchen, cloth washing roomer at public parks.

Furthermore, the Saudi woman has realized both the danger of the agricultural, nutritional products that use insecticides in planting crops and their harmful impact on health and environment. In fact, many Saudi women have displayed a remarkable concern for purchasing organic products in whose manufacturing natural organic fertilizers are used. Additionally, the Saudi woman has become more enlightened in the field of using at home chemical cleaners, such as insecticides preparations, furniture shining sprays, air refreshers whose repeated inhalation proved to be harmful to 
health and environment.

\section{The Strategy of TAKING AdVAntages of THE CONTRIBUTION OF SAUDI WOMEN IN ENVIRONMENTAL DEVELOPMENT}

The activation of the role of a woman in the preservation of an environment constitutes essential aspects of the strategy of environmental development in the Kingdom of Saudi Arabia. Middle Eastern countries lag behind the other countries of the world in relation to the economic opportunity and participation of women [4]. Through performing her various roles in society and which should be respected by all sectors of society, a woman can effectively contribute to the preservation of an environment via doing the following:

- Encourage the woman to inculcate in the minds of her children since their early childhood the value of loving beauty and nature as whatever a child learns during early years can easily be remembered by him without difficulty, and not forgotten.

- Guide the woman always to seek to set good example for her children in the process of preserving water from due wastage; and that she does not allow water taps open for a relatively long time.

- Invite the woman to supervise the consumption of energy at home, and that she must not be allowed to let lights lit and other electrical appliances in an operation status only in necessity.

- Advise the woman to desist from throwing waste materials or food remains from the windows of the car or during walking with her children at the public parks; and that she must teach them to throw the remains of sweets and different types of food they eat at the specified containers and in the appropriate manner.

- Encourage the woman to guide her children to grow the plant at the house court or on the vase on the house balcony and teach him to take care of it.

- Request the female teachers to direct her students regarding environment and develop feeling of responsibility in her mind via the children poems and other school activities such as drawing, etc.

- Urge the woman to conduct within the framework of various women activities enlightenment campaigns to other women on the necessity of observing general cleaning inside and outside homes.

- Request those concerned to support the rural woman so that she can contribute effectively in the process of recycling of waste materials via the usage of food remains as forage to animals.

- Appeal to the woman working as an employee at the sector of municipalities and environment preservation and who takes action, to play a more positive role in taking the correct decision pertaining to the environment [5].

\section{THE Role OF THE WOMAN IN LIMITING THE REDUCTION OF THE NATURAL ENVIRONMENTAL RESOURCES}

In the framework of preserving environment and limiting the reduction of the natural environmental resources, the woman can play a significant role via practicing her activities as a housewife, family affairs supervisors, and the individual responsible for children upbringing. This is in addition to her other significant roles represented in her work as a scholar, doctor (physician), academician and official. This is rightly manifested in the remarkable social status which the woman occupies at her first environment, "home". For, she in most cases arranges the economic affairs of the home via her dealing with the natural resources available at home such as water, food, and energy. However, when the woman recognizes the importance of these resources and their limitation in quantity, this will be a crucial element in reducing the extravagance consumption of food, excessive usage of energy sources and anything that might lead to the wastage of natural resources and increase of waste materials in environment.

If a woman as a housewife is responsible for reducing the resources such as energy and water, she will also play a highly significant educational role. This is represented in directing children to good usage of natural resources such as guiding children to follow suitable style for making use of water, economizing in its consumption, as this represents one of the problems in the Kingdom of Saudi Arabia whose water resource is little.

\section{The Role of Woman In SECURING HeAlthy ENVIRONMENT FOR HER CHILDREN}

The role of a woman can be extended to include the field of securing healthy environment for her children, giving due concern to provide them with good nutrition that is founded to a large extent on the environmentally friendly nutritional products. Furthermore, the housewife should fight air pollution, limit usage of harmful chemicals in cleaning activities, retain such chemicals in places far away from the reach of children, ventilate daily the room by renewing its air and expose it to sun rays as well as encourage her children to acquire ornamentation plants or assist them to grow plants at the home garden. When the woman plays this role, this will help children develop in a healthy way as this will secure for them due protection against diseases and that they will assisted to assimilate the required awareness pertaining to the techniques of good health, correct nutrition and safe environment. In Saudi Arabia, there has been a shortage of female health personnel that are well-trained. This unfavorable situation must be ameliorated [6].

\section{THE PROPER USAGE OF THE FAMILY FOR THEIR CAR}

The woman, who plays the role of the housewife, can contribute to the preservation of the environment via encouraging her family members to the proper usage of their cars the exhausts of cars are considered one of the most significant and prominent causes of environment pollution. Such pollution increases with the increasing number of cars. When the petrol burns up inside the car's engine for obtaining energy, it causes the emission of chemical materials that pollute air and damage environment. Certain countries call families to practice the experiment of dispensing with the 
moving of their car for a week in a month so as to limit the pollution of the environment. This is a good idea, and can be applied, provided that suitable and alternative public transportation means are made available.

\section{The Proper Usage of Chemical Cleaners AND PREPARATIONS INSIDE HOME}

No home is hardly devoid of chemical cleaners \& preparations inside Home, especially those used at kitchen for cleaning plates and cooking containers and utensils. However, the excessive usage of these chemical materials can be detrimental to the health of the family members, who may inhale or touch them, in addition to the damage they may cause to the environment. Here emerges the significant role of a housewife in reducing the usage of these chemical materials and keeping them at places far away from the reach of children. Therefore, the housewives have to either reduce the usage of these chemical cleaners or use them in least possible quantity so as to preserve the environment [7].

\section{Adoption of Waste Recycling System}

Waste recycling system takes advantage of wastes such as (glass, aluminum, paper, plastic and etc.) via their recycling them and re-manufacturing them into useful things that can be used in our daily life. If the woman is a housewife, she can contribute in making this experiment successful by collecting recyclable materials such as glass, paper and metals and putting them in containers specified for each material and by encouraging children to perform this task.

The process of recycling has, in fact, great and basic benefit for the environment. Let's imagine the extent of pollution that affects air, soil, and water. Furthermore, if piles of waste materials and remains are left to accumulate around us without thinking of disposing of them via exploiting them in a beneficial way, the image will no doubt be terribly disturbing! This is in addition to the fact that the process of manufacturing new things from raw materials causes itself the pollution of both air and water in a manner that exceeds the pollution resulting from the recycling process [5].

\section{EnCOURAGING THE WOMAn to PARTICIPATE IN THE DESIGN OF THE CONSTRUCTION ENVIRONMENT}

The Saudi woman can play an effective role in reviving the traditional building type and preserving as well as guaranteeing its continuity. This comprises the preservation of both the Gizani and Hijazi constructional heritage. To increase her contribution in environment, the Saudi woman must be granted necessary incentives to participate in the design and implementation of the constructional environment, especially if we consider the fact many female Saudis enjoys creative perfection in the formation of the Saudi civilization heritage.

Furthermore, the Saudi woman has successful experiments in this field and which are represented in her participation in the traditional construction in both Asir and Gizan Administrative Districts; as women used to paint the walls of the houses with attractive colorful ornamentations that reflect the surrounding and distinctive natural environment [8].

\section{THE INCREASE OF THE SAUdI WOMAN IN ACHIEVING SUSTAINABLE DEVELOPMENT}

Due to lack of rigorous research, the endeavors of Saudi women have not been highlighted [9]. The employment opportunities for the Saudi women are still limited. This resulted in the great increase of the unemployment rates compared with those of men. In social science, one of the most exciting subjects is the economics of development [10]. The Annual Report of the Saudi Arabian Monetary Agency has displayed the high rates of the unemployment among women during the years between 2000 till 2013; and that if conditions continue in the same manner; the increase is anticipated to continue till 2017 (see Fig. 1).

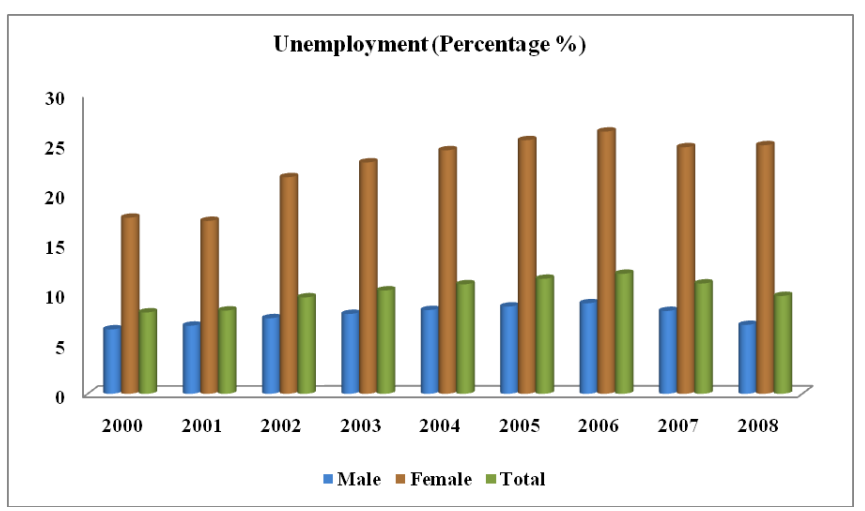

Fig. 1. Comparison of unemployment rates of males and females in the Kingdom of Saudi Arabia.

Source: (Saudi Arabia Monetary Agency: Annual Report

Volumes: 43,44,45,46 and 47 by Population \& Workforce Section)

It is remarked that work opportunities of the woman are generally concentrated on particular occupations, especially those pertaining to the educational sector, for instance. The Fig. 2 below shows the total number of women participate in the labor force (see Fig. 3) and when comparing with the second figure we found that, the majority of women are working in the education field (considering the high rate of unemployment of women).

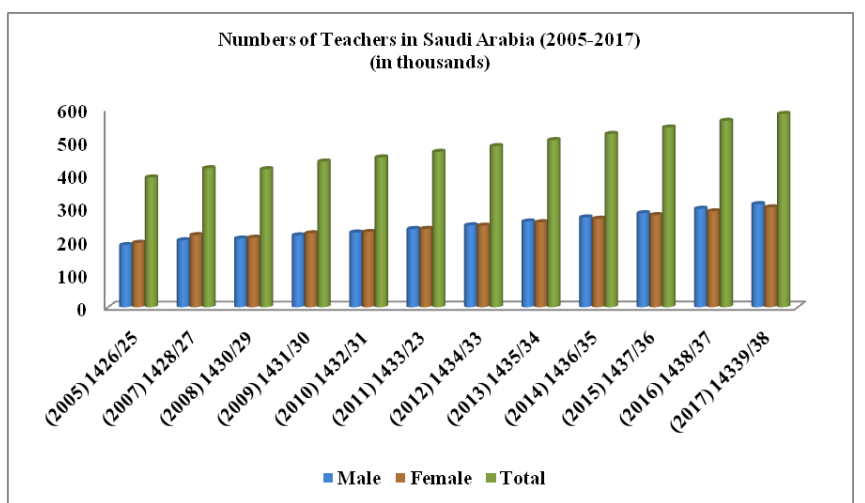

Fig. 2. Numbers of teachers in Saudi Arabia (2005-2017). Source: (Saudi Arabia Monetary Agency: Annual Report Volumes: 43,44,45,46 and 47 by Population \& Workforce Section)

It is therefore suggested that new fields and activities ( not traditional) are to opened for the woman so as to increase her contribution and participation in the development process; 
and these - for instance - include - but not limited to - the following:

- Establish female commercial markets or malls that employ new numbers of female laborers.

- Build female factories, such as carpet factories, women clothes shops and gold and jewelry shops and that employ only women as workforce.

- Set up offices for computer and Internet activities which are exclusively confined to female employment.

- Enter the field of decoration and design development which attracts strongly many women.

- Establish universities for women and secure for them job opportunities.

- Train and qualify certain Saudi women on male -dominated manual and skillful activities such as plumbing and electricity works so as to work inside women facilities and confirm their appointment.

In order to overcome the obstacles that prevent the woman from effective participation in the movement of sustainable development, we propose the following:

- Promulgate new laws and regulations that facilitate the effective participation of the woman in the general economic activity, especially investment one.

- Facilitate public traffic transportation for the woman.

- Increase the training and qualification programs that suit the work of the woman; and contribute to the increase of her participation in filling up the post opportunities available in the work market.

- Increase the chances of academic specialties for females as well as encourage them to join new academic and research fields.

- Encourage the state to establish circles that support the woman such as small project funds that render financial and investment support for the females desiring such support.

- Create mechanisms for the change of the culture of the society so as to accept the presence of women in the open and common work environment.

- Encourage the woman to work in home production and assist her to sell her products.

- Give attention to "distance work" field which creates job opportunities for the woman to work without departing her home via the modern developments at work environment as a result of the usage of computer, Internet and modern communication means.

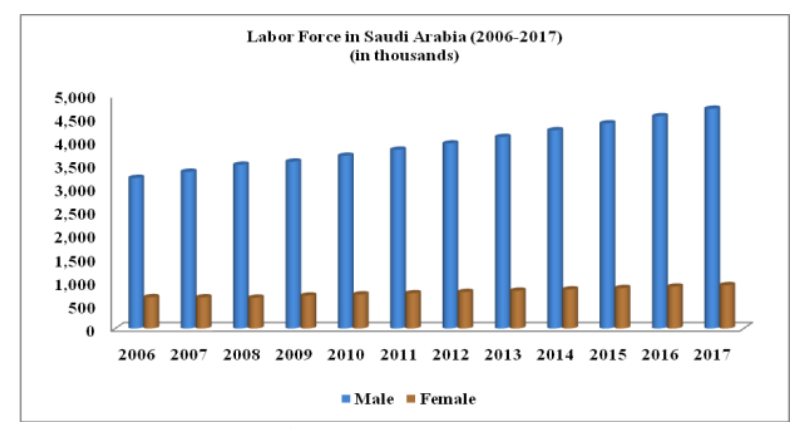

Fig. 3. Labor force in Saudi Arabia (2006-2017).

Source: (Saudi Arabia Monetary Agency: Annual Report

Volumes: $43,44,45,46$ and 47 by Population \& Workforce Section)

\section{SUMMARY}

The activation of the role of a woman in the preservation of the environment constitutes essential aspects of the strategy of environmental development in the Kingdom of Saudi Arabia. This is represented in the significance of the various roles that a woman plays as a housewife, family affairs supervisor, and an individual responsible for children upbringing. This is in addition to her other significant roles represented in her work as a scholar, doctor (physician), academician and teacher. The environmental role of the woman can be extended to secure healthy environment for her children, giving due concern to provide them with good nutrition. This will secure them adequate knowledge of good health techniques and benefit all sectors of society.

\section{REFERENCES}

[1] A. Mobaraki and B. Soderfeldt, "Gender inequality in Saudi Arabia and its role in public health," University of Malmo, 2007.

[2] I. Tinker and B. Bramsen, "Women and world development," American Association for the Advancement of Science, 2008.

[3] E. Cecelski, "The role of women in sustainable energy development," National Renewable Energy, 2000.

[4] K. Marmenout, "Women focused leadership development in the Middle East: Generating local knowledge," The Business School for the World, 2009.

[5] F. Fahimi and V. Moghadam, "Empowering women, developing society: Female education in the Middle East and North Africa," MENA Policy Brief, 2003.

[6] A. Gilani and A. Wehady, "Job satisfaction of female Saudi nurses," Eastern Mediterranean Health Journal, vol. 77, no. 2, pp. 31-37. 2001.

[7] Q. Mustufa, Management of Environment \& Sustainable Development-Second Printing, Al-Dar Al-Jamiah Alexandria, 2010.

[8] D. Wheeler, "Empowering publics: Information technology and democratization in the Arab world," United States Naval Academy, 2006.

[9] D. McKenna, "Women entrepreneurs in Riyadh, Saudi Arabia," University of Maryland University College, 2009.

[10] G. Meier and J. Rauch, Leading Issues in Economic Development, Oxford University Press, 2000.

Haga Abdelrahman Ibrahim El-Imam is an assistant professor in the Department of Economics, Faculty of Economic and Administration at King Abdul-Aziz University. Haga Abdelrahman Ibrahim El-Imam is lecturering the undergraduated and postgraduated students, and teaching micro, macro, quantitative analysis, petroleum economics, money \& banking and feasibilty studies \& evaluation projects. Haga Abdelrahman Ibrahim El-Imam is a consultant in the Strategic Studies Centre from 2014, and the vice head of the Department of Economics at King Abdul-Aziz University. Haga Abdelrahman Ibrahim El-Imam published many researches whose research interests are in applied economics, economic development and sustainable developmen, environmental economics. Haga Abdelrahman Ibrahim El-Imam is a member of Saudi Economic Association (SEA) in 2012 and a member of Saudi Society for Environmental Sciences (SENS) in 2013.

Halah Alattas obtained her bachelor's degree with honor in economics from King Abdulaziz University (KAU) in 2009. She completed her master's degree at the University of Essexin United Kingdom in 2013. She also obtained a high diploma in education from Arab Open University in Jeddah in 2010 in which helped her to develop her teaching and leadership skills. Halah has been working as a teacher assistant at the Economic Department at Faculty of Economics and Administration at KAU since 2010.Her research interests cover topics such as; female labor market analysis, inflation, economics development and unemployment. She has been assigned as the head coordinator of the blackboard systems at the Faculty of Economics and Administration, KAU. She is also a member in activities committees at the Economic Department. 